\title{
Checkpoint Charlie, die Teilung Tirols und die Grenze zu Gibraltar und Melilla
}

\author{
Carmen Castro Moreno
}

Córdoba

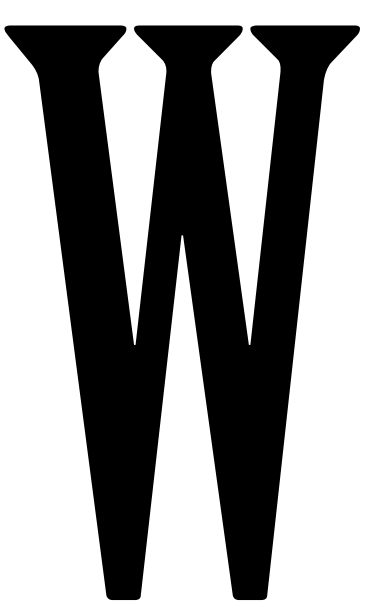

as kann eine Grenze bewirken? Vor allem Trennung...

Zehn Tage nach dem Abriegeln der Berliner Grenze am 13. August 1961 durften ausländische Touristen, Diplomaten sowie das Militärpersonal der Westallierten Ostberlin nur noch über den Grenzübergang Bahnhof Friedrichstraße betreten. Da es keinen eigenen Übergang in Berlin für diese Personen gab, richteten die westlichen Allierten den Übergang in der Friedrichstraße, Ecke Kochstraße, als dritten inne rdeutschen Kontrollpunkt ein.

Die beiden anderen Übergänge befanden sich an der innerdeutschen Grenze bei Helmstedt und in Dreilinden an der Grenze zwischen der DDR und Westberlin. Nach dem Buchstabieralphabet der US-Army wurde der Übergang in Helmstedt «Alpha», in Dreilinden «Bravo» und der Übergang in Berlin «Charlie» genannt.

Hauptaufgabe des Übergangs Checkpoint Charlie war es, westliche Allierte vor dem Betreten Ostberlins zu registriere und über den Aufenthalt in der Hauptstadt der DDR zu informieren.

Die Teilung Ti rols 1919 und der Zweite Weltkrieg 1945 brachten den deutsch - und ladinischsprachigen Südtirolem viele bittere Jahrzehnte. Unter der zentralistischen Verwaltung Roms und vollends unter der Diktatur des Faschismus wurden die deutsche und ladinische Sprache in Schulen und Ämtern verboten. We iters wurden Deutschsprachige und Ladiner von der öffentlichen Verwaltung und von sozialen Einrichtungen ausgeschlossen. Eine harte Bewährungsprobe war die Option, bei der sie entscheiden mussten, ob sie in ein deutsches Land umsiedeln oder italianisiert werden wollten, d.h. weiterhin in Südtirol leben, aber die Ti roler Kultur aufgeben und der italienischen Platz machen. Die Jahrzehnte, die dem Krieg folgten, waren nicht besser; der Zentralismus Roms brachte für den völlig anderen Charakter der Tiroler kein Verständnis auf.

Spanien leitete mehrfach Maßnahmen ein, um die Verwaltung Gibraltars unter Druck zu setzen. So wurde beispielsweise die Grenze mehrfach geschlossen, am längsten von 1969 bis 1985 . Bei einem Volksreferendum im Jahr 2002 stimmten dennoch 99 Prozent der Einwohner für den Verbleib unter britischer Herrschaft und damit gegen eine Rückgabe an Spanien.

Illegale Einwanderer haben ständig versucht, die Grenzanlagen der spanischen Exklave Melilla im Norden Marokkos zu überschreiten. Die afrikanischen Einwanderer sind normalerweise von marokkanischen und spanischen Grenzpolizisten aufgehalten wor- den. Es kommt vor, dass illegale Einwanderer nachts versuchen, die Grenzposten Melillas zu stürmen. Nach Angaben der Stadtverwaltung gelingt es nur wenigen Einwanderern, die mittlerweile zur Festung ausgebaute Grenzanlage zu überwinden.

Bei den Vorfällen handelt es sich um massive Anstürme illegaler Einwanderer auf Melilla. Bei diesen Versuchen, spanisches Territorium zu erreichen, sind schon viele Menschen ums Leben gekommen. Im Jahre 2005 starben bei ähnlichen Vorfällen 14 Immigranten. Zwischen Marokko und Spanien gibt es die beiden Exklaven Melilla und Ceuta betreffend grundlegend unterschiedliche Auffasungen. Rabat betrachtet die beiden Exklaven an der Mittelmeerküste als integralen Bestandteil Marokkos. Die Exklaven sind jedoch seit mehr als 400 Jahren unter spanischer Hoheit.

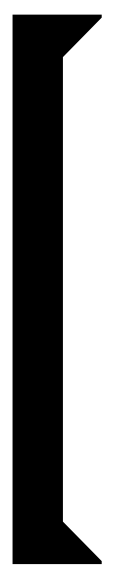

Spanien leitete mehrfach Maßnahmen ein, um die Verwaltung Gibraltars unter Druck zu setzen, so wurde beispielsweise die Grenzemehrfach geschlossen, amlängsten von 1969 bis 1985.

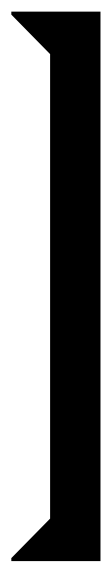

...natürlich sind alle Grenzen historisch wie zeitgeschichtlich irgendwie oder irgendwann das Resultat von Kriegen. Natürlich markieren sie die Trennung von zwei unterschiedlichen Hoheitsgebieten mit allen entsprechenden Konsequenzen, doch dienen sie in friedlichen Zeiten durchaus auch als Begegnungspunkt. Davon unterscheiden sich die beschriebenen vier Fälle grundsätzlich: Sie perpetuier(t)en gewissermaßen einen Konfliktzustand, der immer wieder zu diplomatischen Affronts von höchster Brisanz oder Unruhen führt(e). Dass auf diesem Schauplatz großer Politik die Schicksale kleiner Menschen durch anhaltende Familientrennungen oder andere Repressalien nachhaltig geschädigt werden, ist dabei wohl die eigentliche Tragödie.

(Einer der klügsten Sätze des früheren Bundespräsidenten v. Weizsäcker scheint dem Rechnung zu tragen: «Es kommt nicht darauf an, Grenzen zu beseitigen, sondern ihnen das Trennende zu nehmen.») 
